\title{
PERSPECTIVAS PARA A POLÍTICA FUNDIÁRIA NO ESTADO DEMOCRÁTICO DE DIREITO BRASILEIRO
}

\section{OUTLOOK FOR THE LAND POLICY AS DEMOCRATIC BRAZILIAN LAW}

\author{
${ }^{1}$ Mauê Ângela Romeiro Martins
}

\section{RESUMO}

Considerando que os problemas correlatos à distribuição de terras no Brasil consecutivamente foram preteridos, não tendo havido a satisfação das demandas por democratização de acesso à terra, mas a ratificação de política fundiária excludente e permeada pela manutenção de conflitos fundiários, há necessidade da transcendência da perspectiva estipulada na construções normativas abstratas ao mundo fático, o que nos remete ao objeto do artigo que é refletir sobre a perspectiva para a política fundiária brasileira na constância do Estado Democrático Brasileiro.

Palavras-chave: Política fundiária, Estado democrático de direito, Direitos fundamentais

\begin{abstract}
Whereas related to land distribution in Brazil consecutively problems were unsuccessful, and there was not meeting the demands for democratization of access to land, but the ratification of exclusionary land policy and permeated by the maintenance of land conflicts, no need of transcendence perspective stipulated in the abstract normative constructions factual world, which brings us to the subject of the article is to discuss the outlook for the Brazilian land policy in the constancy of the Brazilian Democratic State.
\end{abstract}

Keywords: Land policy, Democratic state, Fundamental rights

\footnotetext{
${ }^{1}$ Mestranda em Direito Agroambiental pela Universidade Federal de Mato Grosso - UFMT, Mato Grosso (Brasil). E-mail: mauearm@gmail.com
} 


\section{INTRODUÇÃO}

Historicamente as respostas aos problemas relativos à terra no Brasil sempre foram objeto de procrastinação por parte dos governantes de cada época, ou seja, não houveram políticas compromissadas com a resolução dos entraves histórico, social, econômica, étnica e cultural, não satisfazendo as demandas por democratização do acesso à terra, o que enseja a continuidade dos conflitos por ela, havendo ao longo dos séculos apenas a ratificação de uma política de centralização fundiária sob domínio de poucos e mais recentemente uma supervalorização capitalismo agrário.

Nesse contex to, será pontuado ao leitor acerca de fatos da história brasileira no intuito de verificar o perfil das políticas "públicas” por meio dos seus marcos regulatórios e suas consequências sociais, porque o passado é o nascedouro do descontentamento social por ausência de distribuição justa da terra, provocando a ocorrência dos conflitos fundiários hoje, ora que as medidas normativas levaram à formação estrutural rural que é objeto das normas geradoras do perfil da política pública necessária para a resolução das demandas sócioeconômicas-culturais na atualidade.

Em seguida, aponta-se a perspectiva surgida a partir da Constituição de 1988, que institui um Estado Democrático de Direito, no qual a política fundiária precisa agregar a qualificação de pública por corolário dos pressupostos compulsórios que devem permear a política fundiária na recente ordem constitucional.

Feito isso, por fim, serão feitos apontamentos que delatam a perspectiva de eficiência da política fundiária ao que tange à resolução de conflitos e a concretização do interesse público, este atrelado aos ditames correlatos a um Estado Social e Democrático de Direito, porque há necessidade de uma reflexão.

\section{O PERFIL DA POLÍTICA FUNDIÁRIA BRASILEIRA ATRAVÉS DA ANÁLISE DOS MARCOS REGULATÓRIOS}

Apontamentos sobre a trajetória histórica da política fundiária é interessante porque, antes de qualquer coisa, indica que a questão fundiária está estritamente ligada ao processo de desenvolvimento econômico apropriado pelo Brasil (ARAUJO, 1984, p. 4), remetendo-nos aos entraves para a apropriação e aplicação de uma política pública fundiária nos dias de hoje e direcionando-nos ao perfil real e ideal da política. Por isso, nas próximas páginas serão dispostos os dados históricos, brevemente, porque não é esse o objetivo geral do artigo, e 
principalmente históricos regu latórios que nos trazem ao estado político-social atual da questão fundiária brasileira.

\subsection{O regime de sesmarias pela carta foral de 05 de outubro de 1531}

Acontece, segundo Ibrain Rocha et al (2010, p. 57) que o modo de organização fundiária brasileira possui espeque no direito lusitano, por não haver normas próprias para a colônia, sendo instalado formalmente o regime de sesmarias pela Carta Foral de 05 de outubro de 1531, modelo este precipuamente usado por Portugal para corrigir o estado de improdutividade de terras portuguesas.

Porém, as terras brasileiras não eram terras sem ocupação ou improdutivas, porque durante o período do descobrimento haviam inúmeras nações indígenas no território brasileiro, os quais possuíam o seu território por direito próprio e originário, usufruindo de suas vantagens, de sua riqueza, sobretudo a caça, a pesca e os frutos, na qualidade de povos coletores (FERREIRA, 1998, p. 109).

Não obstante a isso, as terras brasileiras passaram a pertencer à coroa portuguesa, o que resultou na ocupação do Brasil, mas inegavelmente, também ocasionou a formação do latifúndio (ROCHA,. et al , 2010, p. 61).

Cabe mencionar um traço feudal do sistema, o que levou a um resultado diferente daquele obtido em Portugal. No Brasil tal traço feudal encaminhou para uma estrutura fundiária baseada na grande propriedade rural, contrariando ao que historicamente aconteceu em Portugal, e outras colônias, onde o sistema originou a pequena propriedade agrícola (FERREIRA,1998, p. 112).

O resultado da implantação do regime de sesmaria no Brasil se justifica como negativo, porque se em Portugal as terras sob incidência desse regime eram poucas e improdutivas; no Brasil as terras eram virgens e em grandes extensões. Em Portugal, política de reforma agrária; no Brasil, política de colonização (MIRANDA, 2009, p.14).

A colonização do Brasil, como outras colônias europeias na América no mesmo período, teve caráter essencialmente mercantilista: ocupar a terra e produzir riquezas para proporcionar renda ao Estado e lucros à burguesia o que é garantido pelo monopólio comercial e pelo pacto colonial, que legitima o direito exclusivo de comprar e vender na colônia por meio de seus comerciantes e de suas companhias (COSTA, 2012, p. 21). 
Nesse ínterim, o que se pode constatar é que a política (pública) fundiária não existia durante o período colonial, pois tinha-se como objetivo a ocupação do território, a fim de obstar a tomada das terras brasileiras por outros colonizadores e para a exploração dos recursos naturais existentes no Brasil, atendendo os anseios mercantilistas europeus, como pode ser observado pela disposição de Araújo:

A ocupação da terra é então feita em função dos interesses mercantis europeus. A produção é realizada por grandes unidades de produção, voltadas para o comércio mundial. Pela imposição dessas condições há necessidade de latifúndios, baseados no trabalho escravo e na monocultura, para os quais, foram cedidas grandes extensões de terra no decorrer do período mercantilista (ARAUJO,1984., p. 4).

Assim, no período colonial $a$ concentração de terras aumentou e se consolidou, vez que no regime escravocrata vigente no Brasil-Colônia não existiam movimentos sociais como os havidos nos últimos séculos em busca da democratização do acesso à propriedade da terra (CARVALHO, 2010, p.262).

\subsection{Período das Posses}

Após, houve um vácuo legal por omissão administrativa e legal (COSTA, 2012, p. 22), lapso que ficou conhecido como período de posses decorrente da suspensão do regime de sesmarias por meio de resolução n. 76 de 17 de julho de 1822 até a promulgação da Lei de Terras em 1850, motivada por clamores de reordenamento do sistema agrário (ROCHA, et al, 2010 p. 61), tinha-se, então, Terra sem lei para regular a aquisição de suas terras, passando a ocorrer a ocupação indiscriminada de terras, à margem do sistema legal (MIRANDA, 2009, p.16).

\subsection{Lei de Terras}

O desligamento do sistema de sesmaria só aconteceu realmente com a Lei de Terras do Império n. 601/1850, a qual instituiu o registro paroquial, comumente denominado de registro do vigário, tendo efeito meramente declaratório (ASSUNÇÂO, 2008, p. 22). Interessa saber sob égide dessa norma que: 
Com a Lei de Terras é instituído uma nova forma de apropriação da terra: a da mediação pelo mercado. As terras devolutas só poderiam ser apropriadas mediante compra e venda, extinguindo-se o regime de posse. Os valores de compra das terras foram elevados, fixando-se preços mínimos superiores aos vigentes na época; os lotes só poderiam ser adquiridos em hasta pública e à vista, com o que, o acesso às terras restringiu-se somente àqueles que tivessem dinheiro imediatamente disponível para comprá-las. Por outro lado, o produto dessas vendas era destinado a financiar a vinda de colonos da Europa (ARAUJO, 1984, p. 6).

Desta feita, ainda que a Lei de Terras tenha sido o primeiro instrumento legal realmente elaborado para regular as questões fundiárias existentes no Brasil, observa-se estar sujeita mais a uma política desenvolvimentista de mercado, pois excluiu a possibilidade de apropriação da terra gratuitamente para restringi-la a mercadoria, o que coaduna com os valores liberais imersos a partir da Revolução francesa e diverge dos fundamentos democráticos (ALBUQUERQUE, 1987, p. 1).

Portanto, ocupar terras (públicas ou particulares) sem a licença de seu dono passou a ser considerado crime, tornando impossível o acesso à terra para quem detinha como capital única e exclusivamente a sua força de trabalho (ROCHA et al.,2010, p. 63).

A Lei de Terras trouxe regramento acerca do reconhecimento de propriedade, que deveria ser feito pela reavaliação das cartas de sesmarias que, ainda que não tivessem preenchidos os requisitos legais, comprovassem o cultivo da terra (COSTA, 2012, p. 23). Para tanto, foi criado pela Lei 1.237/1864 o Registro Geral, tendo o Decreto 3.453/1865 como regulamentador, que foi superado pelo Decreto 169-A/1890. Ainda nesse ano, foi criado o Registro Torrens por força do Decreto 955-A/1890 (ASSUNÇÂO,2008, p. 22), sendo um instrumento do registro público que permite legalizar e sanear posse não fundada em perfeito título de propriedade, que está previsto na legislação vigente no artigo 277 da Lei 6.015/1973 (Lei de Registros Públicos) (COSTA, 2012, p. 23).

No Império não havia falar em política pública fundiária, havendo o incremento do latifúndio que já havia sido disseminado a partir da ideia de implantação de sesmarias de enormes dimensões, não havendo intuito de propiciar o acesso à terra aos camponeses e trabalhadores rurais (COSTA, 2012, p. 18), sendo a Lei de Terras vital para o processo de transformação capitalista brasileiro, ao privilegiar a grande propriedade territorial, uma constante da estrutura fundiária que persiste até os dias atuais (ARAUJO, 1984., p. 8), como pode ser verificado também pelas disposições de Carvalho: 
Com a independência em 1822, a concentração de terras se agravou. No período, os conflitos não envolviam trabalhadores rurais, uma vez que quase todos eram escravizados. As disputas pelas terras brasileiras se deram sob a lei do mais forte, ao poder das armas dos grileiros. Em 1850, o Império editou a Lei de Terras, na tentativa de ordenar o campo e iniciar o controle do território nacional. Seu art.1 proibiu as aquisições de terras devolutas por outro meio que não fosse a compra. Ao impedir a ocupação de terras públicas e determinar que a aquisição de terras só pudesse se dar mediante pagamento em dinheiro, reforçou o poder dos latifundiários ao tornar ilegais as posses de pequenos produtores, excluindo do acesso à terra o grande contingente de escravos que seriam libertos em 1888. Apesar das esperanças geradas, nem a proclamação da República em 15.11.1889, nem a libertação dos escravos um pouco antes, em 13.05.1888, foram capazes de melhorar o perfil da distribuição de terras no país. Ao contrário, o poder político não só continuou nas mãos dos latifundiários, como foi reforçado na figura dos coronéis do interior e de seus currais eleitorais. Libertos, os escravos foram excluídos do acesso à terra pelas vias antes predominantes, pois a Lei de Terras vedou a aquisição de terras devolutas que não fosse por meio da compra. Sem dinheiro para comprar terras, o grande contingente de escravos libertos constituiu o exército de mão de obra barata para a agricultura e indústria (CARVALHO, 2010, p. 262).

Já na fase Republicana a estrutura fundiária não sofreu alteração quanto ao direito de propriedade (ROCHA et al, 2010, p. 66), ou seja, na vigência da Carta de 1891 o poder político continuou nas mãos dos latifundiários. Desde as capitanias hereditárias até os latifúndios modernos, a estrutura fundiária vem sendo mantida praticamente inalterada (COSTA, 2012, p. 24).

Na República Velha (1889 e 1930), imensas áreas foram incorporadas ao processo produtivo, e os imigrantes europeus e japoneses passaram a exercer papel relevante na agricultura nacional (CARVALHO,2010, p. 262).

Cabe lembrar, nessa época foi promulgado o Código Civil de 1916, que não trouxe disposições estritas à questão agrária, ainda que alguns institutos tenham sido estabelecidos, tais como, usucapião, direito de vizinhança etc. (ROCHA et al., 2010, p.66), entendimento que é ratificado nos estudos de Costa:

Reverberando a sempre intangibilidade e quase "imaculado" direito de propriedade, em 1916 foi promulgado o Código Civil de caráter individualista, privatista e sucessório. Graças a este direito de sucessão, as propriedades foram sendo divididas em propriedades menores, entretanto sem perder o caráter monocultor. Isto perdurou até a década de 1960 (COSTA, 2012, p. 26).

Os fatos que seguiram nas décadas de 50 e 60 demonstravam que o latifúndio no Brasil passava por uma arraigada crise, haviam aflorado organizações sociais e movimentos 
reivindicando reformas sociais, especialmente a reforma agrária, inspiradas pelas ideias comunistas (ROCHA et al.,2010, p.66-67).

Nesse contexto, a questão fundiária começou a ser debatida pela sociedade e tida como um obstáculo ao desenvolvimento do país, quando as reformas de base passaram a ser consideradas pelo governo a fim de buscar o desenvolvimento econômico e social do país (COSTA, 2012, p. 26).

Por todo o exposto até o momento, parece realmente acertada a conclusão acerca da política fundiária no Brasil revelada por José Juliano de Carvalho Filho, quando diz:

Desde o período colonial até o início dos anos 60 do século atual, não havia política fundiária no Brasil. Enquanto outros países, entre os quais os Estados Unidos, resolveram de alguma forma as suas questões agrárias, o Brasil permaneceu sem enfrentar esse problema, de grande importância para o seu futuro como Nação soberana, democrática e desenvolvida tanto no campo social, como no econômico. A questão da terra chegou a ser discutida no país por ocasião da Lei de Terras de 1850 e na Campanha Abolicionista, contudo, prevaleceram os interesses do latifúndio (CARVALHO FILHO, 2014, p. 28).

\subsection{Estatuto da Terra}

Foi quando, em meio ao regime militar (1964-1984), promulgou-se a Lei 4.504/1964, dando o primeiro passo para a realização da reforma agrária no país (CARVALHO, 2010, p. 263), o qual visava equilibrar as torsões e distorções sociais por meio de uma política agrícola fundiária e a tentativa de uma reforma agrária, combatendo tanto o latifúndio como o minifúndio, este último considerado fragmentação improdutiva da terra (FERREIRA, 1998, p. 113).

A criação do Estatuto da Terra e a promessa de uma reforma agrária foram as estratégias utilizadas pelos governantes para apaziguar os camponeses e tranquilizar os grandes proprietários de terra (COSTA, 2012, p. 28). [...]. Em vez de promover a reforma agrária, o capitalismo impulsionado pelo regime militar promoveu a modernização do latifúndio, por meio do crédito rural fortemente subsidiado e abundante. Assim, a política fundiária que marcou o período militar caracterizou-se pela não implantação da reforma agrária ordenada pelo Estatuto, que ficou apenas no papel (COSTA, 2012, p. 31).

\subsection{Constituição da República Federativa do Brasil de 1988}

Tendo em vista que no período militar as incursões por direitos relacionados à terra foram praticamente inexistentes, foi com a Constituição Federal de 1988, grande marco regulatório 
do período de redemocratização após o fim da ditadura militar no Brasil, que trouxe novos rumos normativos para a questão fundiária (COSTA, 2012, p. 31-32), vez que:

[...] consolidou a garantia dos direitos difusos, coletivos e das minorias, estabeleceu as bases da política fundiária, determinando a reforma agrária pela desapropriação das terras improdutivas e a sua distribuição aos agricultores sem terra, determinou a demarcação das terras indígenas e garantiu a proteção dos direitos dos índios e o usufruto exclusivo de suas terras, reconheceu o direito de propriedade das terras ocupadas por remanescentes das comunidades de quilombos, assim como solidificou a política ambiental, dispondo sobre a criação de unidades de conservação da natureza e a proteção da biodiversidade. Relativizou o direito de propriedade rural, sujeitando-o ao cumprimento da função social, e criou hipóteses de extinção do domínio e da posse (MIRANDA, 2014, p. 211).

Todo caso, a análise dos antigos governos já sob vigência da Constituição Federal de 1998, realizada por Edson Ferreira de Carvalho, demonstra que:

Sucessivos governos adotaram diferentes políticas diante do problema. O governo Collor o ignorou. O governo Itamar fez muito pouco. O governo do presidente Fernando Henrique Cardoso, contando com significativa maioria parlamentar e sob pressão da sociedade, decidiu fazer da reforma agrária uma das prioridades de seu Governo, firmando compromisso de assentar milhares de famílias. No seu governo, a reforma agrária foi vinculada diretamente à Presidência da República com a criação, em 29 de abril de 1996, do Ministério Extraordinário de Política Fundiária, ao qual se incorporou o INCRA. Em 2003 o Governo Lula elaborou o II Plano Nacional de Reforma Agrária, prometendo qualificar a reforma agrária e assentar 400000 famílias (CARVALHO, 2010, p. 265-266).

Portanto, ainda que exista raízes consolidadas para a concretização de uma política pública fundiária, porque há respaldo constitucional e também decorrente da existência de várias normas infraconstitucionais regu lando os vários sujeitos da política pública (MIRANDA, 2014, p.211), em consonância com o perfil de um Estado Social e Democrático de Direito, abarcando também por meio da força dos grupos de pressão as minorias, como os indígenas, camponeses, quilombolas, povos e comunidades tradicionais (SANSON, 2013, p. 118-124). Numa perspectiva, ainda que, no caso, o clímax da expressão normativa afirmativa dos direitos correlatos à dignidade humana não tenha acontecido ainda, fato é que não tem havido a transcendência da política fundiária para o mundo da vida nem ao menos do que já está certo (MIRANDA, 2014, p.211-222).

Isso pode ser justificado pelos efeitos da influência excessiva do modelo de produção capitalista, o qual foi escolhido para a economia e que se alastrou no espaço agrícola, 
endossando a herança colonial de concentração de terras, o que é explicitado abaixo por Carvalho:

\begin{abstract}
Atualmente, identifica-se na transformação do latifúndio em grande empresa capitalista (agrobusiness) a responsabilidade pela manutenção da estrutura fundiária concentrada. O mercado externo e as demandas da indústria nacional passaram a definir o perfil da agricultura brasileira, baseada largamente no uso de insumos químicos (adubos e agrotóxicos) e na mecanização, impulsionados por incentivos fiscais, subsídios e crédito farto, excluindo a maioria das pequenas e médias propriedades do processo de desenvolvimento. A questão da reforma agrária continua atual no Brasil. De um lado é combatida por determinados segmentos sociais, especialmente grandes proprietários rurais e ambientalistas e, de outro, é impulsionada por pressões sociais dos movimentos organizados dos trabalhadores sem-terra. No meio do conflito, o governo tenta agradar a gregos e troianos, buscando modificar a estrutura fundiária brasileira por meio da desapropriação $e$ redistribuição de terras (CARVALHO, 2010, p. 258).
\end{abstract}

Por outro lado, não há comprometimento e inclinação administrativa, legislativa, judiciaria e do executivo para a resolução das questões atreladas à terra, havendo dependência da vontade política dos detentores do poder, o que corrobora para a insistência da existência do conflito fundiário, que se intensificam com as disparidades sociais (FERNANDES, 2014, p 45).

[...] ]o governo toma posições a favor do agronegócio, devido a predominância do paradigma do capitalismo agrário nos ministérios e a pressão agressiva do poderoso setor da agricultura convencional (FERNANDES, 2014, p 8).

Em vista disso, o resultado da política fundiária atual torna-se excludente, ora que permeada por uma política fundada em ideais capitalistas (ALBUQUERQUE, 2004, p. 82), deixando pessoas à margem da abrangência das percepções de direitos de igualdade, por meio da solidariedade social que deveriam advir de um Estado Social e Democrático de Direito (SANSON, 2013, p.122), o que nos revela que a política fundiária adequada ocorreria por meio da distribuição ou redistribuição da terra agregada das medidas e providências correlatas a possibilitar a permanência do sujeito da política pública na terra, para que não ocorra novo fomento à concentração fundiária, resultando na ineficiência das ações do Estado frente ao vetor do conflito fundiário (CARVALHO, 2010, p. 290-292).

Oportunamente, acerca da postura que se tem obtido do governo frente aos problemas inerentes à questão da terra, é no mínimo esclarecedora as informações relativas ao desequilíbrio entre a política governamental e a realidade social expressado no texto de Carvalho (CARVALHO FILHO, 2014, p. 33) citando Maria da Conceição Tavares (TAVARES, 1997, p.2-4): 
Esse divórcio entre os interesses populares e as prioridades do governo explica por que o presidente afirmou (antes da chegada da marcha dos sem terra a Brasília) que 'o problema da terra, tão antigo quanto o País, não poderá ser resolvido por um governo. Talvez por uma geração’. Obviamente, ninguém pretende que os 3 ou 4 milhões de famílias sem-terra sejam assentados em um ou dois anos; mas é claro que o ritmo estabelecido pelo governo é totalmente insuficiente, pois requereria quase meio século para absorver a atual população dos 'sem-terra', na hipótese remota que essa conseguisse sobreviver a tão longa espera”. O governo garante que as metas da política fundiária estão sendo atingidas, todavia, pouco mudou. Enquanto isso, a tensão social no campo cresce, pois a UDR (e outras instituições do gênero) se reorganiza e a ocorrência de conflitos graves torna-se mais do que provável (CARVALHO FILHO, 2014, p.33).

A partir dessa demonstração de postura política, fica claro a persistência da ausência de interesse no sentido de tornar realidade a política pública fundiária na contemporaneidade, ora que o Estado cria e implanta políticas para o reconhecimento e desenvolvimento dos territórios camponeses somente sob pressão popular (FERNANDES, 2014, p 8), exemplo típico disso é a criação do MDA(Ministério do Desenvolvimento Agrário) no ano 2000, que foi motivada pela longa luta política desencadeada pelo massacre de trabalhadores sem-terra em Eldorado dos Carajás/PA, no ano de 1996 (FERNANDES, 2014, p 35).

Fatos muitos parecidos ocorreram por ocasião do massacre de Corumbiara, dos assassinatos de Chico Mendes e do Padre Josimo (hoje nome de assentamento) e, mais recentemente, coma marcha dos trabalhadores rurais sem-terra para Brasilia. As medidas governamentais atuais podem ser vistas como consequência da importância política assumida pela marcha (CARVALHO FILHO, 2014, p.28).

Havido realizada a exposição sobre os acontecimentos históricos que levaram ao estado atual socioeconômico do homem em relação à terra, parece possível constatar que o sujeito da política agrícola não pode ser apenas os mais apessoados do ponto de vista econômico-socialpolítico, a fim de corroborar com a herança cultural da política de ocupação do passado, mas precisa estar aberta às demandas de toda à sociedade, quando há consideração das minorias, por consequência dos ditames de um Estado Democrático de Direito, porque, em caso contrário, haverá a continuidade do conflito fundiário, ou seja, da disputa pela terra: de um lado, uma dimensão histórica, social, econômica, étnica e cultural; e de outro uma política e institucional (SAUER; MARÉS; 2013, p. 117-122). 


\section{A POLÍTICA FUNDIÁRIA ATUAL}

As disposições referentes a direitos sociais contidos nas Constituições do México (1917) e de Weimar na Alemanha (1919) imersas sob conteúdos garantidores de direitos fundamentais, liberdades públicas e os direitos individuais e coletivos, ditaram os rumos para várias constituições (MIRANDA, 2014, p. 210), recaindo paulatinamente sobre as normas jurídicas referente ao direito de propriedade no Brasil.

Nesse esteio, a Lei 4.504/1964 (Estatuto da Terra) trouxe ao ordenamento jurídico brasileiro aspecto de limitação da propriedade abarcando o valor socioambiental da terra para o ser humano por meio da inserção de dispositivo estabelecendo a necessidade de realizar a função social da propriedade, e com a Constituição Federal de 1988, que tem lastro nos direitos fundamentais ensejadores de dignidade à pessoa humana, por consequência da escolha por implementar um Estado Democrático de Direito, houve a apropriação desse valor (MIRANDA, 2014, p.212), o qual tornou-se o cerne do direito agrário, conforme vislumbrado por Souza Filho e Laranjeira:

O Direito Agrário, tem, assim, como base fundante, a função social da propriedade, isto é, a luta jurídica pela implantação do princípio da Constituição de Weimar, "a propriedade obriga" e daquilo que a Constituição Mexicana chamou de subordinação da propriedade ao interesse comum. [...]. O ideal era assim, assentado na máxima "terra a quem trabalha" ou nenhum trabalhador sem terra e nenhuma terra sem trabalhador (SOUZA FILHO; LARANJEIRA, 1999, p.509).

Por conseguinte, a Constituição da República Federativa do Brasil de 1988 prevê sobre a necessidade de cumprimento da função social da propriedade, especificamente no artigo 186, o qual preceitua:

Art. 186. A função social é cumprida quando a propriedade rural atende, simultaneamente, segundo critérios e graus de exigência estabelecidos em lei, aos seguintes requisitos:

I - aproveitamento racional e adequado;

II - utilização adequada dos recursos naturais disponíveis e preservação do meio ambiente;

III - observância das disposições que regulam as relações de trabalho;

IV - exploração que favoreça o bem-estar dos proprietários e dos trabalhadores. 
Nesse contexto, as Políticas Públicas surgem como ferramentas do Estado Democrático de Direito, pautado também em direitos de terceira geração (solidariedade), modelo adotado pela Constituição brasileira de 1998, para que os objetivos do Estado, dispostos no artigo $3^{\text {o1 }}$ dessa carta magna, sejam realizados, sendo, portanto, importantes instrumentos para a concretização dos Direitos Fundamentais (SMANIO, 2013, p. 12).

Isto se justifica, porque não basta a previsão constitucional acerca de direitos e instrumentos propiciadores de dignidade da pessoa humana, há necessidade de uma atuação eficaz dos poderes e órgãos do Estado, bem como de um trabalho eficiente do governo para que os direitos transponham a abstração normativa e tornem-se parte do mundo da vida (SMANIO, 2013, p. 3).

\section{DEFINIÇÃO DE POLÍTICA PÚBLICA FUNDIÁRIA}

No intuito de perseguir a concretude da ideia sobre o tema, necessário faz-se responder: o que seriam políticas públicas? Essa resposta é facilitada por disposições de Maria Paula Dallari Bucci:

As Políticas públicas, isto é, a coordenação dos meios à disposição do Estado, harmonizando as atividades estatais e privadas para a realização de objetivos socialmente relevantes e politicamente determinados (BUCCI, 1997, p. 91).

Deste modo, pode-se desprender que política pública não se faz restritamente com a força da Lei, ainda que esta represente juridicamente aquela, porque a sua efetividade é apenas alcançada a partir da concatenação de elementos e etapas realizadas pelo legislativo, executivo e judiciário, sendo preciso que exista a combinação de um conjunto extremamente heterogêneo de medidas do ponto de vista jurídico, administrativo, financeiro etc. (DUARTE, 2013, p.19), o que também é objeto de esclarecimento por Smanio, que no mesmo sentido expõe:

[...] parece certo é que as Políticas Públicas se referem a institutos diversos, com incidência em várias áreas do conhecimento e da atuação humana, não podendo ser esgotadas por uma única via ou único sistema (SMANIO, 2013, p.9).

\footnotetext{
${ }^{1}$ C.f. Art. $3^{\circ}$ Constituem objetivos fundamentais da República Federativa do Brasil:

I - construir uma sociedade livre, justa e solidária;

II - garantir o desenvolvimento nacional;

III - erradicar a pobreza e a marginalização e reduzir as desigualdades sociais e regionais;

IV - promover o bem de todos, sem preconceitos de origem, raça, sexo, cor, idade e quaisquer outras formas de discriminação.
} 
Nessa mesma perspectiva, Duarte (2013, p.18) menciona as políticas públicas como uma série de estratégias para fomentar o uso racional dos meios e recursos postos à disposição dos Poderes Públicos para desempenhar as tarefas próprias do Estado Social de Direito, o que nos remete ao entendimento de que para existir política qualificada como pública, precisa existir instituição governamental que a adote.

Luiz Almeida de Miranda (2014,. p.209) contribui para a referida definição, explicitando que a política pública, para ser assim considerada, deve ser imposta a todos os membros da sociedade por quem detenha o já mencionado poder político.

Rememorando o entendimento de Smanio (2013,. p. 10) as políticas públicas pressupõem as relações do Estado com a sociedade, pois que a via da participação dos cidadãos deve ser o método a ser buscado, tanto para sua formulação, quanto para a sua execução, o que coaduna com os pressupostos de um Estado Democrático de Direito.

Sanson (SANSON, 2013, p. 125) citando Leonardo Secchi (SECCHI, 2010, p.2) aduz políticas públicas como:

[..] diretrizes elaboradas para arrostar problema coletivamente relevante, possuindo como elementos a intencionalidade pública e a resposta a um problema público, devendo ser analisadas por uma abordagem multicêntrica, cujo foco não é ente emanador da "policy", mas a natureza do obstáculo a ser superado, razão pela qual não apenas os agentes estatais são protagonistas no estabelecimento das políticas públicas, mas também organizações privadas, organizações não governamentais e organismos multilaterais (SANSON, 2013, p. 125).

Desse modo, política pública consiste nas orientações que determinado Estado adota em relação aos assuntos de interesse comum, temos, v.g., a política econômica, referindo-se aos assuntos relacionados às finanças; política educacional, referente à educação; e a política fundiária que trata da ocupação rural da terra MIRANDA, 2014, p. 209).

Na expressão de Sanson:

A compreensão das "políticas públicas" impõe uma análise multidisciplinar do tema, uma vez que engloba processos concomitantes inter-relacionados, $e$ não pode ocorrer apenas sob âmbito administrativo-governamental, uma vez. que o Estado, a despeito de ser condutor dos ciclos formadores da "policy", não é ator exclusivo na sua realização, impondo, assim, uma interação constante com os destinatários de tais medidas, possibilitando, por seguinte, uma abertura da estrutura estatal a influxos da sociedade civil organizada, recordando-se que não pode substituir na realidade hodierna uma separação estanque entre Estado-sociedade presente no modelo liberal. Outrossim em virtude da própria "socialização do Estado" também não é possível entender a cidadania sob os cânones do pensamento moderno, portanto, não extensível 
à população como um todo, com sua seara particular protegida da intervenção do Estado e a participação política restrita à escolha de representantes, devendo-se transmudá-la para uma noção atrelada ao ideal de solidariedade, permitindo, pois, uma participação ativa dos cidadãos nas instituições públicas (SANSON, 2013, p. 140).

Nesse ponto, após breve disposição acerca de política pública, no intuito de situar o leitor sobre este instrumento para que a concretização dos objetivos do estado sejam viabilizados, o qual segundo preceito de solidariedade adstrito à essência do Estado Democrático de Direito, deve-se visar os interesses de todos e para todos, e tendo em vista que a política pública versará sobre diversos assuntos, ora que não são poucos os problemas a serem contornados, resta apontar acerca do objeto da política (pública) fundiária. Para tanto, vejamos a definição disposta por Ferreira:

A política agrária é o conjunto de princípios fundamentais e de regras disciplinadoras do desenvolvimento do setor agrícola. Deve levar em conta o elemento humano para a sua valorização, pois o homem é o ponto central do processo agrícola, bem como o solo, fator importante da produção, associados ao trabalho, à tecnologia, ao capital, ao espírito e à criatividade do empresário dentro de determinados ciclos de produção agrícola. [...]. A política fundiária, por sua vez, difere da política agrícola; é um capítulo da política agrícola, uma parte especial desta, tendo em vista o disciplinamento da posse da terra e seu uso adequado. A política fundiária deve visar e promover o acesso à terra daqueles que saibam e produzir, dentro de uma sistemática moderna, especializada e profissionalizada. A terra tem uma função social, que é justamente a produção agrícola para alimentar a população humana e a sociedade urbanizada (FERREIRA, 1998, p. 157).

As disposições contidas na dissertação de mestrado de Costa colaboram para esclarecer o objeto da política fundiária:

A política fundiária no meio rural compreende regularização do domínio e da posse territorial, com o objetivo de promover e disciplinar o acesso à terra para quem produz, dentro de uma sistemática moderna de produção voltada para o progresso socioeconômico, que permite a autonomia produtiva eficaz, indispensável para o desenvolvimento do país. O surgimento da política fundiária se insere na temática do desenvolvimento rural integrado $e$ sustentado, como um conjunto de ações que permeiam os conflitos e tensões sociais no campo, dentro do contexto de ações preocupadas com o desenvolvimento da produção, do bem estar social com vistas a manter o crescimento econômico constante, ligado direta ou indiretamente à exploração e utilização dos recursos naturais nos diversos ramos de sua atividade agropecuária.[...] Deste modo, a reestruturação fundiária está em sintonia com os princípios garantidores da efetivação da reforma agrária, não se desvinculando da garantia de justiça social, conforme o artigo $16^{2}$ do Estatuto da Terra (Lei 4.504/64) (COSTA, 2012, p. 90-91). 
Por fim, traz-se a contribuição de Miranda (2014, p. 209), no qual explica que a política pública fundiária tem por base o conjunto de normas jurídicas, cujo objetivo é estabelecer direitos e obrigações na relação do homem com a terra.

Nessa linha de raciocínio, parece que a política fundiária, que está fundada precipuamente na Constituição Federal de 1988 (Título VII, Capítulo III, artigos 184 a 191), devendo se direcionar ao interesse coletivo e que, para tanto, utiliza-se da premissa de cumprimento da função social da propriedade para permanecer na direção do interesse público, possui o condão de propiciar o acesso à terra às pessoas com perfil agrário, o que é obstado pela ausência de distribuição justa de terras.

Nesse ínterim, surge a reforma agrária, na tentativa de solucionar impasses na seara campesina, como instrumento para a realização da distribuição de terras no Brasil, nos quais os seus efeitos seriam a ocupação soberana e equilibrada do território, a promoção da geração de empregos e renda, a garantia da segurança alimentar, a preservação do meio ambiente e o desenvolvimento regional (COSTA, 2012, p. 91).

\section{PERSPECTIVAS DA POLÍTICA PÚBLICA FUNDIÁRIA}

As disposições trazidas até o momento coadunado ao posicionamento disposto no Relatório, sob coordenação de Sergio Sauer e Carlos Frederico Marés (2013, p. 2), possibilitam constatar que, historicamente, as políticas públicas fundiárias do Estado brasileiro não satisfizeram as demandas por democratização do acesso à terra, em que pese tenham sido obtidos importantes avanços na criação de novos projetos de assentamentos de reforma agrária, criação de unidades de conservação, demarcação das terras indígenas, titulação de territórios quilombolas.

Isto se justifica porque, como corolário da nova ordem, há na vigente política fundiária disposição referente a direitos difusos, coletivos e das minorias. Assim, nessa perspectiva o âmbito da política fundiária atual abarca os seguintes sujeitos: os camponeses, que almejam a efetivação da reforma agrária por ocasião do conteúdo dos artigos $1^{\circ}$, III e IV; $3^{\circ}$, I e III; $5^{\circ}$

\footnotetext{
${ }^{2}$ C.f. Art. 16. A Reforma Agrária visa a estabelecer um sistema de relações entre o homem, a propriedade rural e o uso da terra, capaz de promover a justiça social, o progresso e o bem-estar do trabalhador rural e o desenvolvimento econômico do país, com a gradual extinção do minifúndio e do latifúndio.

Parágrafo único. O Instituto Brasileiro de Reforma Agrária será o órgão competente para promover e coordenar a execução dessa reforma, observadas as normas gerais da presente Lei e do seu regulamento.
} 
caput e XXIII; 170, III e VII; 184 e 186 da Constituição Federal de 1988; os indígenas, buscando a demarcação de seus territórios alicerçam-se nos artigos $1^{\circ}$, III e IV; $3^{\circ}$, I, III e IV; $5^{\circ}$, XI; 170, VI e VII; 215, §1; 216, II; 231 e 232, todos da Constituição Federal de 1988; os quilombolas, perseguindo a titulação de seus territórios, consubstanciado no conteúdo dos artigos $1^{\circ}$, III e IV; 3º I, III e IV; 170, VII; 215, §1 e 216, II da Constituição Federal de 1988; os povos e comunidades tradicionais, que visam a regularização dos direitos territoriais, sociais, ambientais, econômicos e culturais, os quais possuem direitos previstos no texto constitucional nos $\operatorname{artigos} 1^{\circ}$, III e IV; $3^{\circ}$, I, III e IV; 170,III, VI e VII; 186, II e IV; 215, § $1^{\circ}$;. 216, II (por analogia); 231; t, 68, ADCT (c.f. Decreto 6.040/2007) (SAUER, MARÉS, 2013, p. 120). Mas, também abarca o meio ambiente, por ocasião do conteúdo do artigo 225, da Constituição Federal de 1988, que institui política de preservação do meio ambiente (MIRANDA, 2014, p. 211).

Todo caso, é fato que ainda que exista um arcabouço normativo reunindo à política pública fundiária afirmação de direitos sobre a terra de diferentes sujeitos e exista no âmbito dessa política proteção aos direitos de meio ambiente saudável e equilibrado, acontece que a questão econômica tem interferido drasticamente na seara fundiária, de tal forma que a possibilidade de democratização do acesso à terra é obstaculizada pela apropriação de um modelo de produção e ocupação da terra individualista, o que é explicitado abaixo:

O desenvolvimento do capitalismo no campo brasileiro, desde o latifúndio ao agronegócio, ocorre à base do continuo processo de expropriação e exploração de povos tradicionais como os indígenas, quilombolas, ribeirinhos, seringueiros, babaçueiros, pantaneiros, caiçaras, jangadeiros, pescadores artesanais, sertanejos, camponeses, entre outros. Esses povos são chamados de tradicionais, mas não com a conotação de povos sem mobilidade histórica ou atraso tecnológico e econômico. São chamados de tradicionais porque todas as mudanças e modernização não foram suficientes para mudalos, no que diz respeito a suas culturas e relação com a natureza (FERNANDES, 2014, p 45). [...]. Esse modelo de desenvolvimento da agricultura que passa a preconizar um maior rendimento da exploração agrícola é responsável por graves impactos sociais e ambientais (FERNANDES, 2014, p. 49).

Tendo isso em vista, José Eli da Veiga, em estudo acerca do não favorecimento social pela manutenção de uma estrutura fundiária baseada na agricultura patronal, reverbera:

Com base na experiência histórica dos países de Primeiro Mundo, deve-se pensar a passagem da economia brasileira para uma fase socialmente articulada de desenvolvimento que dificilmente poderá prescindir de um conjunto de políticas públicas que venha a fortalecer, aqui também a 
agricultura familiar. E este é o argumento central deste artigo: a necessidade de favorecer o desenvolvimento da agricultura familiar no Brasil. E é esse objetivo estratégico que dá sentido à reforma agrária. Precisamos de uma reforma agrária. Precisamos de uma reforma agraria que desafogue os minifundistas oferecendo-lhes a oportunidade de se tornarem agricultores familiares viáveis; uma reforma agrária que transforme arrendatários em proprietários; uma reforma agrária que ofereça terra aos filhos dos pequenos proprietários; enfim, uma reforma agrária cuja diretriz central seja o fomento e o apoio a nossa agricultura familiar. Isso só será possível, evidentemente, se a política agrícola deixar de favorecer escandalosamente o segmento patronal da agropecuária brasileira, que ganhou muita força nos últimos vinte anos devido ao apego de nossas elites ao modelo pré-fordista de crescimento (VEIGA, 1991. p. 62-63).

Diante do contexto de complexidade dos pressupostos que concorrem para a efetivação de uma política pública aos auspícios de um Estado Social e Democrático de Direito, nota-se que o grande desafio é fazer com que a atuação do Estado volte-se para a garantia e ampliação dos direitos fundamentais (DUARTE, 2013, p.40), perspectiva essa que daria substância aos ditames constitucionais inerentes às minorias para que emergissem da construção abstrata para o mundo da vida, no qual Duarte ${ }^{3}$ contribui para a temática:

O fato é que no âmbito do estado Social e Democrático de Direito, o que se exige, como já destacado, é a ação coordenada dos Poderes Públicos em prol da efetivação dos direitos, destacando-se ainda, a atuação da sociedade civil, que deve assumir uma postura ativa não apenas no processo de elaboração das políticas públicas - por meio de sua presença em Conselhos de direitos, audiências públicas, além da iniciativas referentes ao chamado "orçamento participativo" - como também nas instâncias de fiscalização e controle, o que pode ocorrer, justamente, por meio da propositura de ações judiciais (DUARTE, 2013, p.30). [...] Um aspecto urgente para melhorar essa situação diz respeito à adoção de um sistema de indicadores técnico-científicos capazes de mensurar os avanços e retrocessos na aplicação dos direitos sociais, conforme recomendação da Conferência de Direitos Humanos de Viena, ocorrida em 1993. Este é um exemplo que permite julgar, segundo parâmetros objetivos, a progressividade de sua implementação dos direitos fundamentais (DUARTE, 2013, p. 40).

\section{CONSIDERAÇÕES FINAIS}

Ao final, pôde-se absorver que, por regra, as manifestações normativas de contexto fundiário do passado inerentes ao Brasil não possibilitaram perspectivas de democratização da terra, mas o endosso de um perfil de política fundiária excludente calcado em ideais liberais, o que resulta, inclusive nos dias de hoje, em conflitos.

3 
Mas, indiscutivelmente as influências estrangeiras trouxeram à seara brasileira a valorização de direitos de solidariedade propiciadores de normas Constitucionais que afirmassem o direito de minorias à terra, o que está inserido na Constituição da República Federativa do Brasil de 1988.

Todo caso, a presença de disposições normativas não bastam para a concretização de direitos, há necessidade de efetividade das disposições disparadas pela Constituição, resultando em políticas públicas fundiárias, porque ainda que exista arcabouço normativo referente à povos indígenas, quilombolas, camponeses, povos e comunidades tradicionais, para a preservação e defesa do meio ambiente saudável para a fruição da presente geração e para as futuras, o grande entrave é realizar os direitos hoje reconhecidos, bem como ampliá-los no intuito de possibilitar dignidade da pessoa humana para todos, o que nos remete à necessidade de realização de uma política pública fundiária, segundo preceito de solidariedade adstrito à essência do Estado Democrático de Direito, fundamentado nos interesses de todos e para todos.

\section{REFERÊNCIAS BIBLIOGRÁFICAS}

ALBUQUERQUE, Francisco José Batista de; COELHO, Jorge Artur Peçanha de Miranda; VASCONCELOS, Tatiana Cristina. As políticas públicas e os projetos de assentamento. In: Estudos de Psicologia 2004, 9(1), p. 81-88. Disponível em: http://www.scielo.br/pdf/epsic/v9n1/22384.pdf Acesso em: 26 jun 2014.

ALBUQUERQUE, Marcus C. Cavalcanti de. Estrutura fundiária e reforma agrária no Brasil. Revista de Economia Política, vol 7,n. 3, jul/set/1987. Disponível em: < https://mailattachment.googleusercontent.com/attachment/u/0/?ui=2\&ik=df0a4d7802\&view=att\&th=146ddfb741 565341\&attid=0.2\&disp=inline\&safe=1\&zw\&saduie=AG9B_P8U9V xhdKjr3Fwy_q3rRr4R\&sadet=1 403893125561\&sads=vUDJGIvuFHySGe3fcGtw9H 1Gr8> Acesso em: 26 jun 2014.

ASSUNÇÂO. Lutero Xavier. Direito Fundiário Brasileiro: ensaio, legislação rural e urbana, parcelamento do solo, registro. Bauru, SP: Edipro, 2008.

ARAUJO, Luiz Ernani Bonesso de. A questão fundiária na ordem social. Dissertação, 1984. Disponível em: < https://repositorio.ufsc.br/bitstream/handle/123456789/106227/321100.pdf?sequence=1> Acesso em: 25 jun 2014.

BRASIL. Constituição (1998). Constituição da República Federativa do Brasil: promulgada em 5 de outubro de $1988 . \quad$ Disponível em : http://www.planalto.gov.br/ccivil_03/Constituicao/ConstituicaoCompilado.htm> Acesso em: 25 jun 2014.

BUCCI, Maria Paula Dallari. Politicas públicas e o direito administrativo. In: Revista de Informação Legislativa. Brasília, a. 34, n. 133, jan/mar 1997.

CARVALHO, Edson Ferreira de. Manual didático de direito agrário. Curitiba: Juruá, 2010, p.262 
CARVALHO FILHO, José Juliano de. Política fundiária oportunidades perdidas, revolução cultural e lampedusa. Disponível em: 〈http://produtos.seade.gov.br/produtos/spp/v11n02/v11n02_03.pdf> Acesso em: 20 jun 2014.

COSTA, Alfredo Pereira da. Agência Nacional de Política Fundiária: alternativa para a efetividade da função social da propriedade privada rural (Dissertação de Mestrado). Marília: UNIMAR, 2012, $181 \mathrm{f}$.

DUARTE, Clarice Seixas. O ciclo das políticas públicas. In: SMANIO, Gianpaolo Poggio; BERTOLIN, Patricia Tuma Martins (orgs). O Direito e as políticas públicas no Brasil. São Paulo: Atlas, 2013.

FERNANDES, Bernardo Mançano;GONÇALVES ,Elienai Constantino WELCH, Clifford Andrew (Org).Políticas fundiárias no Brasil- Uma análise geo-histórica da governança da terra no Brasil. Disponível em: http://www.landcoalition.org/sites/default/files/publication/1372/FramingtheDebateBrazil_Portuguese. pdf Acesso em: 20 jun 2014.

FERREIRA, Pinto. Curso de direito agrário. 3 ed. São Paulo: Saraiva, 1998.

MIRANDA, Alcir Gursen de. Direito constitucional agrário brasileiro: delimitação da matéria. In: BARROSO, Lucas Abreu; MANIGLIA, Elisabete, MIRANDA, Alcir Gursen de (cood.). A Lei agrária nova. Curitiba: Juruá, 2009. vol. 2., p.14

MIRANDA, Luiz Almeida. Política fundiária no ordenamento jurídico agrário. Disponível em: < https://mail-

attachment.googleusercontent.com/attachment/u/0/?ui=2\&ik=df0a4d7802\&view=att\&th=146ddfb741

$565341 \&$ attid $=0.6 \&$ disp $=$ inline $\&$ safe $=1 \& z w \&$ saduie $=$ AG9B_P8U9V xhdKjr3Fwy_q3rRr4R\&sadet $=1$ 403893129003\&sads=-jQM9BHo-dZrhejMMGgvDlvRJ7Q > Acesso em: 26 jun 2014.

ROCHA, Ibraim; TRECCANI, Girolamo Domenico; BENATTI, José Heder; HABER, Lilian Mendes; CHAVES, Rogério Arthur Friza. Manual de direito agrário constitucional: lições de direito agroambiental. Belo Horizonte: Fórum, 2010.

SANSON, Alexandre. Os grupos de pressão e a consecução de políticas públicas. In: SMANIO, Gianpaolo Poggio; BERTOLIN, Patricia Tuma Martins (orgs). O Direito e as políticas públicas no Brasil. São Paulo: Atlas, 2013.

SAUER, Sérgio; MARÉS, Carlos Frederico (Coord).Casos emblemáticos e experiências de mediação: análise para uma cultura institucional de soluções alternativas de conflitos fundiários rurais. Brasília: Ministério da Justiça, Secretaria de Reforma do Judiciário, 2013.

155 p. - (Diálogos sobre a Justiça). Disponível em: < http://terradedireitos.org.br/wpcontent/uploads/2014/02/Pesquisa-Conflitos-Fundi\%C3\%A1rios-Agr\%C3\% A1rios-Terra-de-

Direitos.pdf > Acesso em: 07 de jul de 2014.

SECCHI, Leonardo. Políticas públicas: conceito, esquemas de análises e casos práticos. São Paulo: CengageLearning, 2010.

SMANIO, Gianpaolo Poggio. Legitimidade jurídica das políticas públicas: a efetivação da cidadania. In: SMANIO, Gianpaolo Poggio; BERTOLIN, Patricia Tuma Martins (orgs). O Direito e as políticas públicas no Brasil. São Paulo: Atlas, 2013

SOUZA FILHO, Carlos Frederico Marés.de. LARANJEIRA, Raymundo (Coord). Direito agrário brasileiro. São Paulo: LTR, 1999.

TAVARES, M. da C. “A questão agrária”. Folha de São Paulo. São Paulo,27/04/97. 
VEIGA, José de Eli da. Fundamentos do Agro-reformismo. In: Revista Lua Nova, n. 23, 1991. Disponível em: $<$ http://www.scielo.br/pdf/ln/n23/a04n23.pdf $>$ Acesso em: 17 de jul de 2014. 